\title{
Meta-Analysis: The Effect of Screen Time and Fast-Food Intake on Obesity in Children and Adolescents
}

\author{
Salwa Annisaa'), Yulia Lanti Retno Dewi²), Eti Poncorini Pamungkasari2) \\ 1)Masters Program in Public Health, Universitas Sebelas Maret \\ ${ }^{2)}$ Faculty of Medicine, Universitas Sebelas Maret
}

\section{ABSTRACT}

Background: Obesity has reached epidemic proportions worldwide, making obesity a serious global public health challenge. Obesity is not only found in adults but also in children and adolescents which can lead to various physical and mental health problems that are detrimental to the quality of life and are very risky into adulthood. Obesity in children and adolescents today is caused by a lifestyle that makes a person increase in consuming fast food, lack of sleep and the longer duration of screen time. This study aims to analyze the effect of screen time and fast food on obesity in children and adolescents.

Subjects and Method: This was a systematic review and meta-analysis. Population= children and adolescents, Intervention = screen time and fast food, Comparison= no screen time and no fast food, Outcome= obesity. Article searches through journal databases include: PubMed, Science Direct, Google Scholar and Springerlink. The articles used in this study are articles that have been published from 2011-2021. The keywords used are obesity OR obese OR overweight AND "fast foods" OR snacks OR "fried foods" AND "social media" OR "screen time" OR television AND child OR adolescent. Articles were selected with the help of PRISMA flow diagrams. The inclusion criteria included full-text articles with a cross-sectional study design. The analysis used logistic regression with adjusted odds ratio and published in English. Articles that have met the requirements are analyzed using the Revman $5 \cdot 3$ application.

Results: Fifteen articles came from Nepal, China, Pakistan, Canada, Darussalam, Ethiopia, Italy, Australia, Indonesia. Meta-analysis of 8 cross-sectional studies showed that screen time 3 hours/ day can affect obesity in children and adolescents 2.4 times compared to screen time $<3$ hours/ day. The results of the meta-analysis in 8 cross-sectional studies showed that fast food 3 times/ week had an effect on obesity in children and adolescents by 2.74 times compared to fast food $<3$ times/week.

Conclusion: The long duration of screen time and the frequency of consuming fast food often increase the risk of obesity in children and adolescents.

Keywords: obesity, screen time, fast foods, meta-analysis

\section{Correspondence:}

Salwa Annisaa. Masters Program in Public Health. Universitas Sebelas Maret, Jl. Ir. Sutami 36A, Surakarta 57126, Central Java, Indonesia. Email: salwaannisaa@gmail.com. Mobile: 081541180488 .

\section{Cite this as:}

Annisaa S, Dewi YLR, Pamungkasari EP (2021). Meta-Analysis: The Effect of Screen Time and FastFood Intake on Obesity in Children and Adolescents. J Health Promot Behav. 06(02): 164-175. https://doi.org/10.26911/thejhpb.2021.06.03.01.

(i) J Journal of Health Promotion and Behavioris licensed under a Creative Commons

Attribution-NonCommercial-ShareAlike 4.o International License.

\section{BACKGROUND}

Obesity has reached epidemic proportions worldwide, making obesity a serious global public health challenge. Obesity is not only found in adults but also in children and adolescents. More than 340 million chil- 
dren and adolescents aged 5-19 years were obese in 2016. The prevalence of overweight and obesity in children in the world has increased 10 times, from 11 million to 124 million within 40 years (WHO, 2021)..

Obesity in children and adolescents can lead to various physical and mental health problems that are very detrimental to the quality of life and are very risky into adulthood. Eighty percent of 10-year-old children with a BMI above the 95th percentile will remain overweight into adulthood. Obesity in children can also cause feet growth disorder, sleep disorder, sleep apnea, lack of confidence, diabetes mellitus, coronary heart disease, osteoarthritis and cancer (Kurniawan, 2018).

There are several studies in the last two decades which report that the incidence of obesity varies in each country as a result of different lifestyles and diets and there is no significant relationship between the obesity level of a country and its economic status. Countries that have a high prevalence of obesity include (Nauru 61\%, Cook Island 55.9\%, Palau 55.3\%, Kuwait 37.9\%, United States 36.2\%, Jordan 35.5\%, Saudi Arabia $35.4 \%$, Qatar 35.10\%). The obesity rate in Indonesia is $6.9 \%$ or as much as 276,361,783 (WPR, 2021). Indonesia has a high obesity rate, namely among adolescents, almost $15 \%$ of adolescents are overweight or obese and in the group of children this problem is estimated to affect $8 \%$ of children.

Obesity prevention strategies have been recommended and adopted at individual and national levels, but the prevalence of obesity continues to increase in various segments of the population in both developped and developing countries. One way that is currently used to prevent and reduce obesity is to provide education to the public to make behavioral changes and increase physical activity (James et al., 2001).
Public awareness about obesity has changed substantially, in the early 2000 s only $2 \%$ to $3 \%$ of the world's population considered obesity as one of the most important health problems, but now many people have considered obesity as an important problem. Despite the increased awareness and willingness to accept obesity as a clinically significant chronic condition, someone who is obese will still experience negative stigma and discrimination in society (Sikorski et al., 2011).

According to Puhl \& Heuer (2009) that someone who is obese tends to be discriminated against in terms of work, health care and interpersonal relationships. Currently, there are still $65 \%$ of mothers who do not realize that obesity in children is an important health problem, lack of knowledge about obesity in children can pose new challenges in intervening because there is a misperception about obesity which is a manifestation of poor health but is considered by the community as a health problem. sign of good health.

Many parents believe that obesity in children and adolescents is caused by genetic factors but do not consider other factors such as environmental factors, eating habits and physical activity. The impact of the emergence of the digital environment is unquestionable. Children and youth in many parts of the world today are growing up with computers, tablets, and mobile phones. The current generation spends more time in front of the screen than the previous generation. Various studies have examined the impact of screen time such as using social and digital media on child development, obesity, and mental health. In general, people understand that the longer duration of screen time will have negative impacts such as poor sleep patterns, unbalanced nutritional intake, poor social interactions, and poor family life. Various studies 
have proven that public perceptions are limited and often obscured by confounding factors such as socioeconomic groupings and negative behavior (Anuradha, 2019).

Various studies have proven that food intake in children and adolescents and lack of physical activity can cause obesity, but in recent years there has been no systematic review and meta-analysis of research results regarding the influence of fast food consumption habits and screen time playing habits. on the incidence of obesity in children and adolescents. So, the authors are interested in conducting a systematic review and meta-analysis of the results of studies involving obesity in children and adolescents, the habit of consuming fast food and the habit of playing in front of the screen (screen time).

\section{SUBJECTS AND METHOD}

\section{Study Design}

This was a systematic review and meta-analysis, using PRISMA flow diagram guidelines. Search articles through journal databases including PubMed, Google Scholar and Science Direct and Springerlink. The articles used in this study are articles that have been published from 2011-2021.

The keywords used in the database search were obesity OR obese OR overweight AND "fast foods" OR snacks OR "fried foods" AND "social media" OR "screen time" OR television AND child OR adolescent

\section{Inclusion Criteria}

In this study, the inclusion criteria were full text articles using a cross sectional study design in English, the analysis used was multivariate with adjusted Odds Ratio (aOR), Intervention in the form of exposure to screen time and fast food, study subjects are children and adolescents aged 5-19 years (women and men), the outcome is obesity.

\section{Exclusion Criteria}

Exclusion criteria in this study included articles published before 2011, articles on primary studies with RCT and observational studies other than cross-sectional (cohort and case-control), primary studies that had meta-analyses conducted and articles that used non-English languages.

\section{Operational Definition of Variables}

In formulating the research problem, PICO is used here. The population is children and adolescents aged 5-19 years. Intervention is screen time 3 hours/day and fast food 3 times/week with comparison, screen time < 3 hours/day and fast food $<3$ times/week. The outcome is obesity.

Screen time is time spent passively watching screen-based entertainment (TV, computers and gadgets) but does not include active screen-based games that require physical activity to play them. (Kaye et al., 2020). Time spent in front of screen 3 hours in one day.

Fast food is food sold in restaurants or shops with ingredients that are cooked, heated and served to customers in packaged form to be taken out or taken away (Islam and Ullah, 2010). Consuming fast food $>3$ times a week.

Obesity is excessive fat accumulation due to an imbalance in energy intake (energy intake) with energy used (energy expenditure) for a long time (Kemenkes, 2018).

\section{Instruments}

An assessment of the quality of research articles was carried out using the Critical Appraisal Checklist for cross-sectional Study published by CEBM University of Oxford 2014 (CEBM, 2014).

\section{Data Analysis}

Articles were collected using PRISMA Flow diagrams and analyzed using the Review Manager (RevMan) 5.3 application by calculating effect size and heterogeneity to determine the combined research model 
and form the final result of the metaanalysis.

\section{RESULTS}

This study deals with the effect of screen time and fast food on the incidence of obesity in children and adolescents consisting of 15 articles from 5 continents, namely
4 studies from the Asian continent and 7 studies from the African continent, a study from the America, a study from the Australian continent, and 2 studies from the European continent.

The search for articles was carried out using a database based on the PRISMA flow diagram in Figure 1.

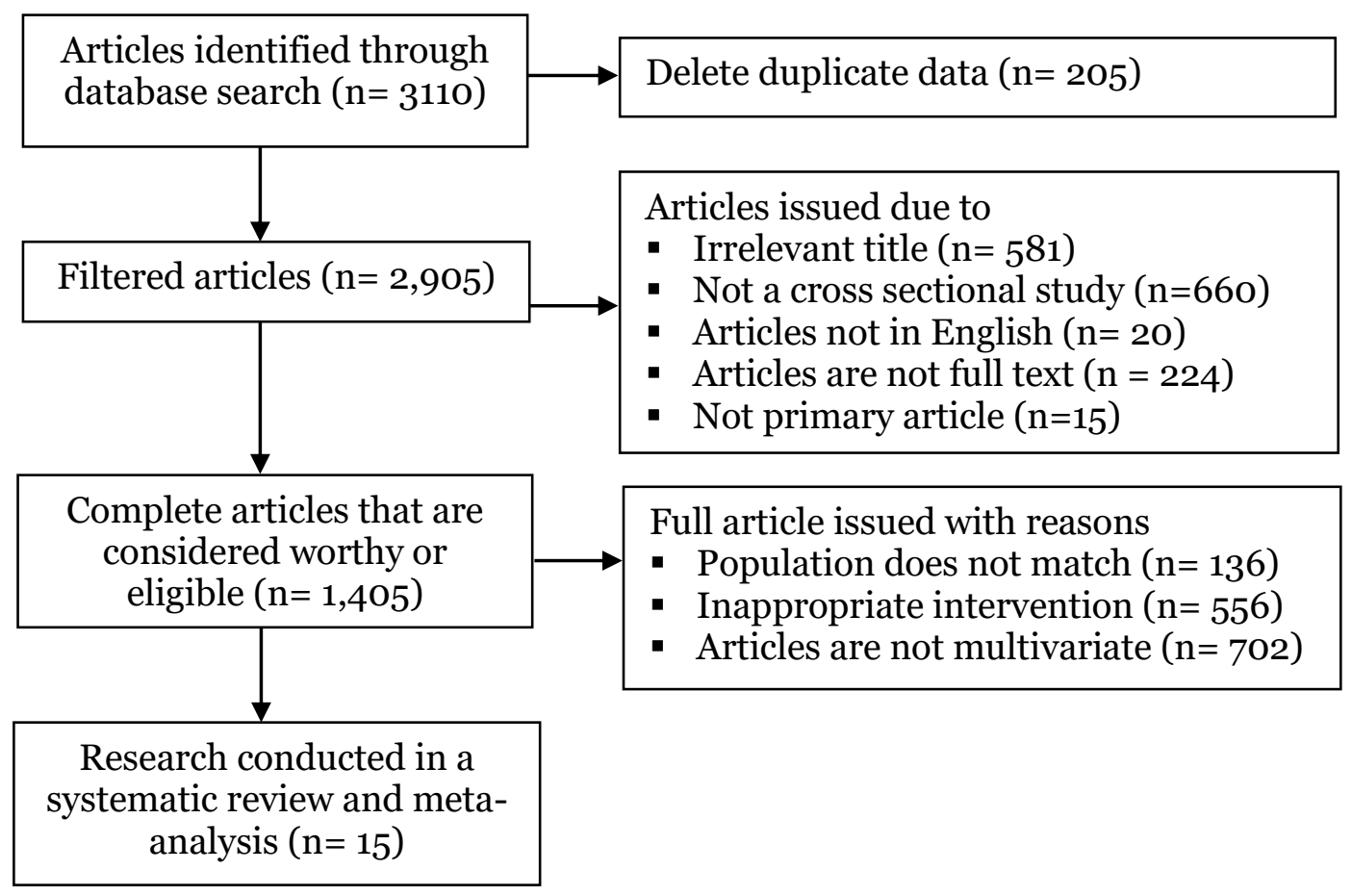

Figure 1. Results of Prisma Flow Diagrams

\section{Research Quality Assessment}

Assessment of the quality of research articles using the Critical Appraisal Checklist for cross-sectional study which can be seen in table 1. The criteria for evaluating articles with cross-sectional study design are as follows:

1. Does the study formulate the research question (research problem) clearly?

2. Is the cross sectional research method appropriate to answer the research question?

3. Is the method for selecting research subjects clearly described?

4. Does the sampling technique not introduce bias (selection)?
5. Is the sample representative of the research target population?

6 . Is the sample size based on consideration of the results of previous studies regarding statistical power?

7. Is the minimum response rate achieved?

8. Is the instrument in determining screen time and fast food valid and reliable?

9. Has statistical significance been tested?

10. Did the researcher report confidence intervals?

11. What confounding factors have been taken into account?

12. Are the results applicable in practice or in the community? 
Annisaa et al./ Screen Time and Fast-Food Intake on Obesity in Children and Adolescents

After assessing the quality of the study, 15 articles were divided into 2 categories according to the dependent variable included in the quantitative synthesis of meta-analysis using RevMan 5.3.

Table 1. Research Quality Assessment

\begin{tabular}{|c|c|c|c|c|c|c|c|c|c|c|c|c|c|}
\hline \multirow{2}{*}{ Primary Study } & \multicolumn{12}{|c|}{ Criteria } & \multirow[t]{2}{*}{ Total } \\
\hline & $\mathbf{1}$ & 2 & 3 & 4 & 5 & 6 & 7 & 8 & 9 & 10 & $\mathbf{1 1}$ & 12 & \\
\hline Piryani et al. (2016) & 1 & 1 & 1 & 0 & 1 & 1 & 1 & 1 & 1 & 1 & 1 & 1 & 11 \\
\hline Hadi et al. (2020) & 1 & 1 & 1 & 1 & 1 & 1 & 1 & 1 & 1 & 1 & 1 & 1 & 12 \\
\hline Karki et al. (2019) & 1 & 1 & 1 & 0 & 1 & 1 & 1 & 1 & 1 & 1 & o & 1 & 10 \\
\hline Andegiorgish et al. (2011) & 1 & 1 & 1 & 1 & 1 & 1 & 1 & 1 & 1 & 1 & $\mathrm{O}$ & 1 & 11 \\
\hline Gali et al. (2017) & 1 & 1 & 1 & 1 & 1 & 1 & 1 & 1 & 1 & 1 & 1 & 1 & 12 \\
\hline Mwaikambo et al. (2015) & 1 & 1 & 1 & 1 & 1 & 1 & 1 & $\mathrm{O}$ & 1 & 1 & 1 & 1 & 11 \\
\hline Desalew et al. (2017) & 1 & 1 & 1 & 1 & 1 & 1 & 1 & 1 & 1 & 1 & 1 & 1 & 12 \\
\hline Mekonnen et al. (2018) & 1 & 1 & 1 & 1 & 1 & 1 & 1 & 1 & 1 & 1 & o & 1 & 11 \\
\hline Teshome et al. (2013) & 1 & 1 & 1 & 1 & 1 & 1 & 1 & 1 & 1 & 1 & $\mathrm{O}$ & 1 & 11 \\
\hline Gebremichael and Chere (2015) & 1 & 1 & 1 & 1 & 1 & $\mathrm{O}$ & 1 & 1 & 1 & 1 & 1 & 1 & 11 \\
\hline Shegaze (2015) & 1 & 1 & 1 & 1 & 1 & 1 & 1 & 1 & 1 & 1 & 1 & 1 & 12 \\
\hline Borghese et al. (2015) & 1 & 1 & 1 & 1 & 1 & 1 & 1 & 1 & 1 & 1 & 1 & 1 & 12 \\
\hline Mihrshahi et al. (2017) & 1 & 1 & 1 & 1 & 1 & 1 & 1 & 1 & 1 & 1 & 1 & 1 & 12 \\
\hline Paduano et al. (2021) & 1 & 1 & 1 & $\mathrm{O}$ & 1 & 1 & 1 & 1 & 1 & 1 & $\mathrm{O}$ & 1 & 11 \\
\hline Paduano et al. (2020) & 1 & 1 & O & 1 & 1 & 1 & 1 & 1 & 1 & 1 & 1 & 1 & 11 \\
\hline
\end{tabular}

\section{Effect of Screen time on Obesity}

\section{a. Forest Plot}

The interpretation of the results of the meta-analysis process can be seen through the forest plot. In Figure 2 it can be seen that there is high heterogeneity ( $\mathrm{I} 2=90 \%$; $\mathrm{p}<0.001$ ), so the forest plot data analysis used a random effect model. Then the results showed that screen time 3 hours / day in children and adolescents had a risk of obesity 2.40 times compared to adolescents who did screen time $<3$ hours $/$ day (aOR = 2.40; $95 \% \mathrm{CI}=1.37$ to $4.21 ; \mathrm{p}<0.001)$.

\section{b. Funnel Plot}

Figure 3 shows the Funnel Plot of the effect of screen time on the incidence of obesity in children and adolescents. The funnel plot shows a publication bias which is characterized by an asymmetric distribution of the estimated results of the primary study, this is indicated by the imbalance in the distance between studies on the right and left sides of the funnel plot.

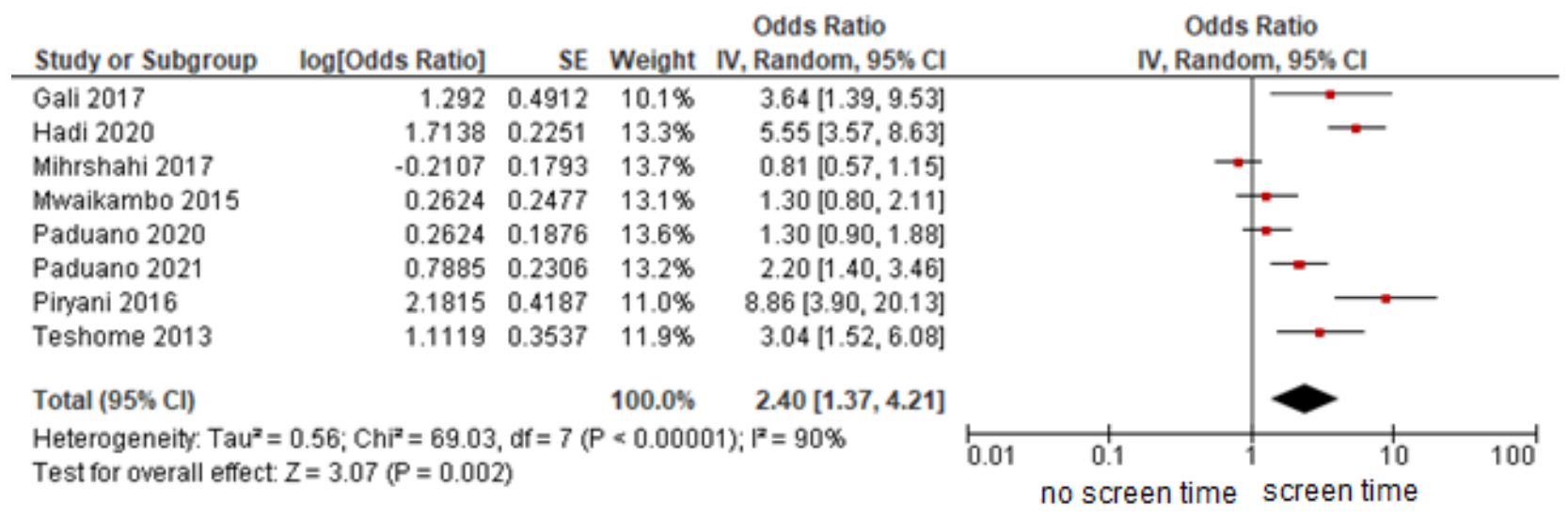

Figure 2. Forest Plot Effect of Screen time on Obesity 
Annisaa et al./ Screen Time and Fast-Food Intake on Obesity in Children and Adolescents

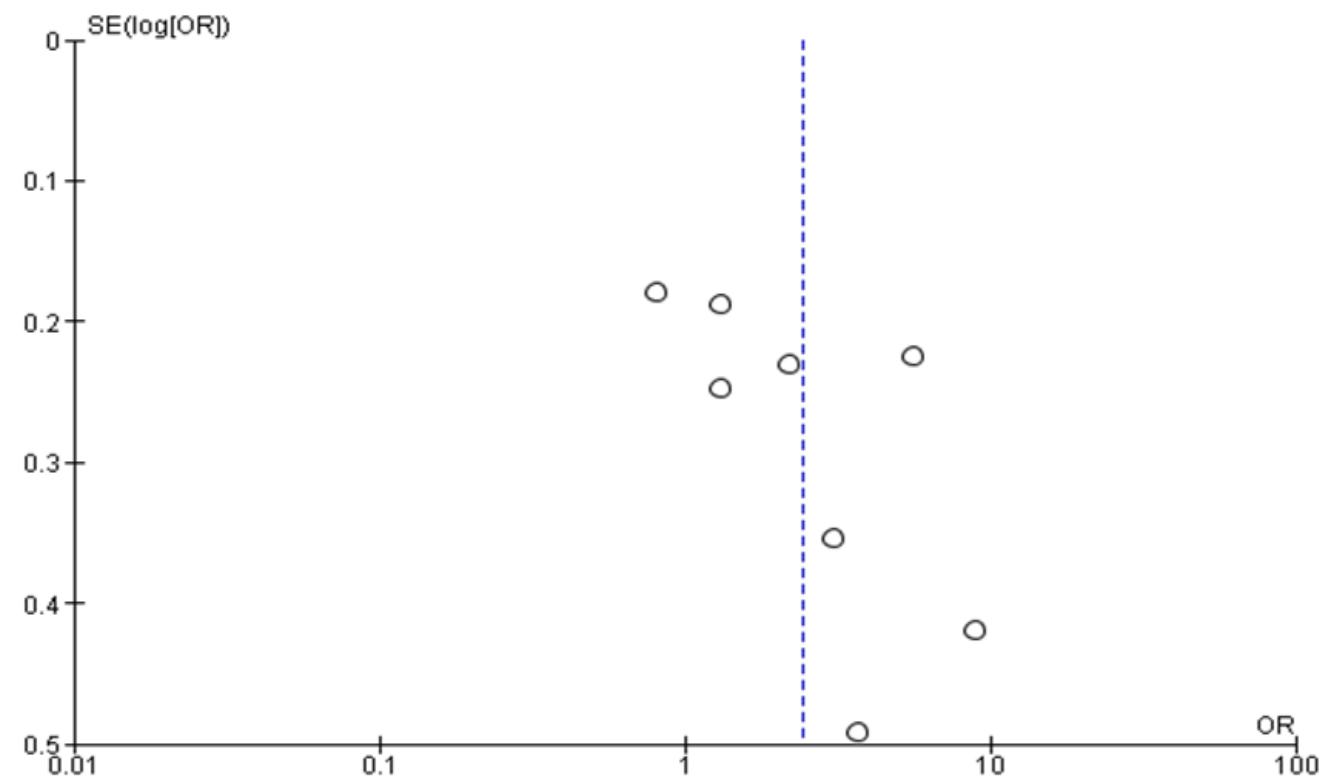

Figure 3. Funnel Plot Effect of Screen time on Obesity

\section{The Effect of Fast Food on Obesity}

\section{a. Forest Plot}

The interpretation of the results of the meta-analysis process can be seen through the forest plot. In Figure 4 it can be seen that there is high heterogeneity $\left(\mathrm{I}^{2}=70 \%\right.$; $\mathrm{p}=0.002$ ), so the forest plot data analysis used a random effect model. The results of the meta-analysis showed that fast food 3 times/week had an effect on the incidence of obesity in children and adolescents 2.74 times compared to children and adolescents who consumed fast food $<3$ times/week
$(\mathrm{aOR}=2.74 ; 95 \% \mathrm{CI}=1.77$ to $4.28 ; \mathrm{p}=$ 0.002).

\section{b. Funnel Plot}

Figure 5 shows the Funnel Plot of the influence of fast food on the incidence of obesity in children and adolescents. The funnel plot shows no publication bias, which is indicated by a symmetrical distribution of the estimated primary study results, the right plot is 4 and the left plot is 3 , while there is 1 plot that touches the vertical line.

\begin{tabular}{lrrrr} 
Study or Subgroup & log[Odds Ratio] & SE & Weight & IV, Random, 95\% Cl \\
\hline Andegiorgish 2011 & 0.708 & 0.2119 & $16.7 \%$ & $2.03[1.34,3.08]$ \\
Borghese 2016 & 0.3293 & 0.4202 & $11.6 \%$ & $1.39[0.61,3.17]$ \\
Desalew 2017 & 0.47 & 0.4218 & $11.6 \%$ & $1.60[0.70,3.66]$ \\
Gebremichael 2015 & 3.2347 & 0.6876 & $6.9 \%$ & $25.40[6.60,97.75]$ \\
Hadi 2020 & 0.4886 & 0.2392 & $16.0 \%$ & $1.63[1.02,2.60]$ \\
Karki 2019 & 1.0716 & 0.2882 & $14.8 \%$ & $2.92[1.66,5.14]$ \\
Mekonnen 2018 & 1.3558 & 0.5129 & $9.7 \%$ & $3.88[1.42,10.60]$ \\
Shegaze 2015 & 1.6094 & 0.366 & $12.9 \%$ & $5.00[2.44,10.24]$ \\
Total (95\% Cl) & & & $100.0 \%$ & $2.74[1.77,4.25]$ \\
Heterogeneity. Tau ${ }^{2}=0.26 ; \mathrm{Ch}^{2}=22.97, \mathrm{df}=7(\mathrm{P}=0.002) ; \mathrm{I}^{2}=70 \%$ \\
Test for overall effect: $\mathrm{Z}=4.50(\mathrm{P}<0.00001)$
\end{tabular}

Figure 4. Forest Plot Effect of Screen time on Obesity 


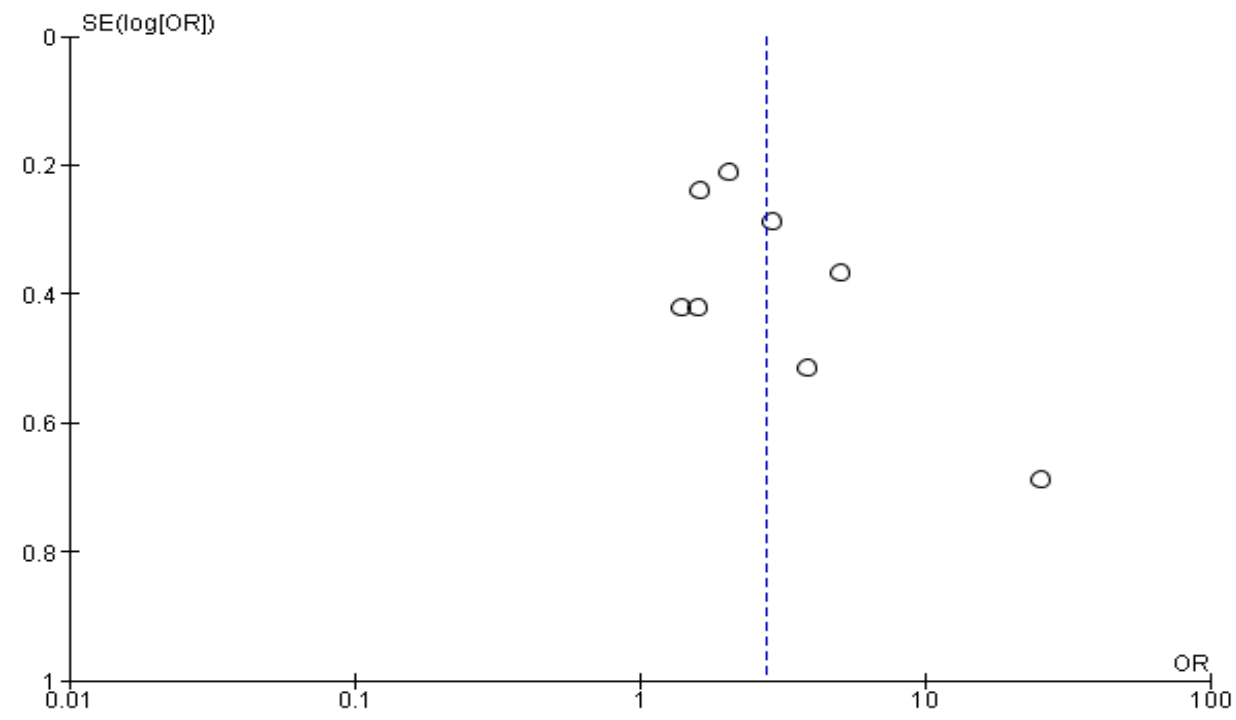

Figure 5. Funnel Plot Effect of Screen time on Obesity

\section{DISCUSSION}

This systematic review and meta-analysis takes the topic of the effect of screen time and fast food on the incidence of obesity in children and adolescents. The independent variables in this study were screen time and fast food and the dependent variable analyzed was the incidence of obesity. This intervention was designed with the aim of reducing the risk of obesity in children and adolescents aged 5-19 years with a cross sectional study design.

Research on obesity in children and adolescents is still considered important, this is because the prevalence of obesity in children and adolescents is still high throughout the world so that it becomes a problem in almost all countries, both developed and developing countries.

There are 8 intervention articles in the systematic review identified from 5 continents from 2011 - 2021. This systematic review and meta-analysis study uses research that has controlled for confounding factors or confounding factors by looking at the inclusion criteria of the primary studies used previously and with the results multivariate analysis in the form of adjus- ted Odds Ratio (aOR). Confounding factors can be interpreted as combining estimates of the relationship between exposure and disease or with exposure, so that confounding factors can affect the relationship or effect of exposure to the occurrence of the disease estimated by the study is not the same as the actual relationship or effect that occurs in the target population with in other words the study results are not correct (Murti, 2018).

The data processing of the effect of screen time and fast food on the incidence of obesity in this study used the Review Manager 5.3 application with the generic inversion variance method. This method is a method used in analyzing data in the form of level data such as time to event data, hazard ratios, ordinal scales, adjusted estimates and average differences or average ratios. The results of the systematic review and meta analysis are presented in the form of forest plots and funnel plots. A forest plot is a diagram that shows an overview of the information from each of the studies examined in the meta-analysis and estimates of the overall results, in which the forest plot also visually displays the magni- 
tude of variation (heterogeneous) between study results. The funnel plot shows the relationship or relationship between the effect size of the study and the sample size or standard error of the effect size of the various studies studied (Murti, 2018). The possibility of publication bias in the funnel plot can be seen from the asymmetry of the number of studies on the right and left sides.

\section{Screen time on Obesity Events}

The results of the meta-analysis using 8 cross sectional studies as a source of metaanalysis of the effect of screen time on obesity in children. The results of the forest plot show that screen time 3 hours/day has an effect on increasing obesity in children and adolescents as much as 2.4 times compared to children and adolescents who are not exposed to screen time $<3$ hours/day $(\mathrm{aOR}=2.40 ; 95 \% \mathrm{CI}=1.37$ to 4.21; $\mathrm{p}<0.001)$. This meta-analysis study provides evidence that screen time has an effect on increasing obesity in children and adolescents.

The results of this study are in line with Frayon et al (2020) in New Caledonia on 954 children from various ethnic groups, namely Malaynesia, Polynesia and Europe and different social levels. The results in this study indicate that the frequency of exposure to the use of screens (tv/com/ gadget) is mostly found in the Malenesians and Polynesians, while the highest risk of obesity is also found in Malenesian (OR= 1.67) and Polynesian ( $\mathrm{OR}=5.40)$ adolescents. As for this meta-analysis, the authors did not examine cultural factors and social levels. This is in accordance with Anuradha (2019) Many people believe that obesity in children and adolescents is caused by genetic factors but does not consider other factors such as eating habits and physical activity. Various studies have proven that screen time exposure can have negative impacts such as unbalanced nutritional intake.

Another similar study was conducted by Martens et al (2017) with a sample of 933 children aged 5 years, this study states that watching TV >1 hour/day has an effect on increasing the risk of obesity in children by 1.72 times compared to children who watch $\mathrm{TV}<1$ hours/day (OR=1.72 ; 95\% $\mathrm{CI}=1.16-2.54 \mathrm{p}=0.001)$. This meta-analysis study is different from previous study, in which the study analyzed the effect of TV > 1 hour, while the meta-analysis study looked at the effect of screen time 3 hours/ day. Screen time is time spent passively watching screen-based entertainment (TV, computers and gadgets) but does not include active screen-based games that require physical activity to play them (Kaye et al., 2020).

\section{Fast food on Obesity}

The results of the meta-analysis on the influence of fast food on the incidence of obesity in children and adolescents contained 8 primary articles with a cross sectional study design as a source of meta-analysis of the influence of fast food on obesity in children and adolescents. The results of the forest plot show that consuming fast food 3 times/week has an effect on increasing obesity by 2.74 times compared to children and adolescents who consume fast food $<3$ times/week (aOR= $2.74 ; 95 \% \mathrm{CI}=1.77$ to $4.25 ; \mathrm{p}=0.002$ ). This meta-analysis study provides evidence that consuming fast food 3 times/ week increase the risk of obesity in children and adolescents.

The results in this study are in line with Febriani and Sudiarti (2019) in Indonesia on 145 children aged 9, 10 and 11 years. The result of this study is that children who consume fast food 3 times/week can increase obesity in children by 2.25 times compared to children who consume fast food $<3$ times/week $(\mathrm{OR}=2.25 ; 95 \% \mathrm{CI}=1.03-4.89$; $\mathrm{p}=0.021)$. Another study by Emond et al. 
(2020) states that the increase in body weight status increases linearly with each time added fast food by 1.38 times greater than those who do not consume fast food $(\mathrm{OR}=1.38 ; 95 \% \mathrm{CI}=1.13$ to $1.67 ; \mathrm{p}=0.001)$.

Fast food is fast food favored by children and teenagers today, because it is practical, tasty and filling. Delicious taste caused by increased primordial palatability due to the high content of sugar, fat and salt. Another characteristic of fast food is that it tends to contain high energy, has a saturated fat content, a low fiber and micronutrient content, and a high glycemic index (Rosenheck, 2008). Frequent consumption of fast food without a balance in energy expenditure through increased physical activity can increase the risk of being overweight/obese.

\section{AUTHOR CONTRIBUTION}

Salwa Annisaa is the main author who chooses the topic, conducts a search for data collection in this study. Yulia Lanti Retno Dewi and Eti Poncorini Pamungkasari conducted data analysis and review studies.

\section{FUNDING AND SPONSORSHIP}

This study is self-funded.

\section{CONFLICT OF INTEREST}

There is no conflict of interest in this study.

\section{ACKNOWLEDGMENT}

The authors would like to thank all those who have helped in compiling this article and also thank the database providers PubMed, Science Direct and Google Scholar and spinerlink.

\section{REFERENCES}

Aggarwal B and Jain V (2017). Obesity in Children: Definition, Etiology and Approach. Indian J Pediatr 2017 85:6, 85(6): 463-471. doi: 10.1007/S12098017-2531-X.
Andegiorgish AK, Wang J, Zhang X, Liu X and Zhu $H$ (2011). Prevalence of overweight, obesity, and associated risk factors among school children and adolescents in Tianjin, China. Eur $\mathrm{J}$ Pediatr 2011 171:4, 171(4): 697-703. doi: 10.1007/So0431-011-1636-X.

Anuradha B (2019). Screen time. J Trop Pediatr. Oxford Academic, 105-106. doi: 10.1093/tropej/fmzo14.

Ardeshirlarijani E, Namazi N, Jabbari M, Zeinali M, Gerami H, Jalili RB, Larijani B and Azadbakht L (2019). The link between breakfast skipping and overweigh/obesity in children and adolescents: a meta-analysis of observational studies. $\mathrm{J}$ Diabetes Metab Disord, 18(2): 657-664. doi: 10.1007/S40200-019-00446-7.

Ardic C and Omar E (2019). Obesity frequency and related risk factors in primary school children. Eur Res Jl, 5(3): 467-472. doi: 10.18621/EURJ.395207 .

Ashakiran S and Deepthi R (2012). Fast foods and their impact on health. JKIMSU, 7-15.

Bharati S, Pal M, Shome S, Roy P, Dhara P and Bharati $P$ (2017). Influence of socio-economic status and television watching on childhood obesity in Kolkata. Homo: internationale Zeitschrift fur die vergleichende Forschung am Menschen, 68(6): 487-494. doi: 10.1016/J.JCHB.2017.08.005.

Biswas T, Islam A, Islam MS, Pervin S and Rawal LB (2017). Overweight and obesity among children and adolescents in Bangladesh: a systematic review and meta-analysis. Public health, 142: 94-101. doi: 10.1016/J.PUHE.2016.10.010.

Borghese MM, Tremblay MS, Leduc G, Boyer C, Bélanger P, LeBlanc AG, Francis C and Chaput J-P (2015). 
Television viewing and food intake during television viewing in normalweight, overweight and obese 9- to 11year-old Canadian children: a crosssectional analysis. $\mathrm{J}$ nutr sci, 4. doi: 10.1017/JNS.2014.72.

CASP (2018). Critical Appraisal Skills Programme (CASP) for Cross Sectional Study. CASP.

Chooi YC, Ding C and Magkos F (2019). The epidemiology of obesity. Metabolism - Clinical and Experimental, 92: 6-10. doi: 10.1016/J.METABOL.2018.09.005.

Cochrane (2014). RevMan 5.3 User Guide. New York. The Cochrane Collaboration.

Damayanti S, Gultom L, Herdanto A, Lestari E, Sidiartha IG and Maxitalia M (2014). Diagnosis tata laksana dan pencegahan obesitas pada anak dan remaja (Diagnosis, management and prevention of obesity in children and adolescents). I. Jakarta: IDAI.

Desalew A, Mandesh A and Semahegn A (2017). Childhood overweight, obesity and associated factors among primary school children in dire dawa, eastern Ethiopia; a cross-sectional study. BMC Obesity, 4(1): 1-10. doi: 10.1186/S40608-017-0156 2/TABLES/5.

Emond JA, Longacre MR, Titus LJ, Hendricks K, Drake KM, Carroll JE, Cleveland LP and Dalton MA (2020). Fast food intake and excess weight gain over a 1-year period among preschool-age children. Pediatric obesity, 15(4). doi: 10.1111/IJPO.12602.

Febriani D and Sudiarti T (2019). Fast food as drivers for overweight and obesity among urban school children at Jakarta, Indonesia. J Gizi Pangan, 14(2): 99-106. doi: 10.25182/JGP.2019.14.2.99-106.

Frayon S, Wattelez G, Paufique E, Nedjar-
Guerre A, Serra-Mallol C and Galy O (2020). Overweight in the pluriethnic adolescent population of New Caledonia: Dietary patterns, sleep duration and screen time. The Lancet Regional Health - Western Pacific, 2: 100025. doi: 10.1016/j.lanwpc.2020.100025 .

Gali N, Tamiru D and Tamrat M (2017). The Emerging Nutritional Problems of School Adolescents: Overweight or Obesity and Associated Factors in Jimma Town, Ethiopia. J Pediatr Nurs, 35: 98-104. doi: 10.1016/J.PEDN.2017.03.002.

Galpin A and Taylor G (2018). The British Psychological Society Promoting excellence in psychology Children, adolescents and screen use. Available at: www.bps.org.uk/behaviourchange (Accessed: 9 November 2021).

Gebremichael B and Chere A (2015). Prevalence of Childhood Overweight and Obesity and its Determinant Factors Among Elementary School Children in Addis Ababa, Ethiopia: A Cross Sectional Study. J Nutr Disorders Ther, 05(04). doi: 10.4172/2161-0509.S1-002.

Gibney M, Margets B, Kearney JM and Arab L (2009). Gizi kesehatan masyarakat (Public health nutrition). Jakarta: EGC.

Hadi H, Nurwanti E, Gittelsohn J, Arundhana AI, Astiti D, West KP and Dibley MJ (2020). Improved Understanding of Interactions between Risk Factors for Child Obesity May Lead to Better Designed Prevention Policies and Programs in Indonesia. Nutrients, 12(1). doi: 10.3390/NU12010175 .

Hannon TS, Rao G and Arslanian SA (2005). Childhood obesity and type 2 diabetes mellitus. Pediatrics, 473- 
Annisaa et al./ Screen Time and Fast-Food Intake on Obesity in Children and Adolescents

480. doi: 10.1542/peds.2004-2536.

Harris JL, Bargh JA and Brownell KD (2009). Priming Effects of Television Food Advertising on Eating Behavior. Health Psychology, 28(4): 404-413. doi: 10.1037/aoo14399.

Hayyat MU, Munir A, Shahzad L and Farhan M (2019). Assessing the nexus of fast food consumption and childhood obesity in Lahore Metropolitan City of Pakistan. Int $\mathrm{J}$ Biosci(IJB), 14(04): 95-102. doi: 10.12692/ijb/14.4.95-102.

Hill D, Ameenuddin N, Chassiakos YR, Cross C, Radesky J, Hutchinson J, Boyd R, Mendelson R, Moreno MA, Smith J and Swanson WS (2016). Media use in school-aged children and adolescents. Pediatrics, 138(5). doi: 10.1542/PEDS.2016-2592/60321.

Hu J, Ding N, Yang L, Ma Y, Gao M and Wen D (2019). Association between television viewing and early childhood overweight and obesity: A pair-matched case-control study in China. BMC Pediatrics, 19(1): 1-8. doi: 10.1186/S12887-019-15579/TABLES/3.

Islam N and Ullah GMS (2010). Factors affecting consumers' preferences on fast food items in Bangladesh. JABR, 26(4): 131-146. doi: 10.19030/jabr.v$26 \mathrm{i} 4.313$.

James PT, Leach R, Kalamara E and Shayeghi M (2001). The worldwide obesity epidemic. Obesity research, 9 Suppl 4. doi: 10.1038/OBY.2001.123.

Kakinami L, Barnett TA, Séguin L and Paradis G (2015). Parenting style and obesity risk in children. Preventive Medicine, 75: 18-22. doi:10.1016/J.YPMED.2015.03.005.

Kane S, Conus S, Haltom D, Hirshorn K, Pak Y and Vigdorchik J (2010). A shoulder health survey: correlating behaviors and comorbidities with shoulder problems. Sports health, 2(2): 119-34. doi: 10.1177/1941738109338358.

Karki A, Shrestha A and Subedi N (2019). Prevalence and associated factors of childhood overweight/obesity among primary school children in urban Nepal. BMC public health, 19(1). doi: 10.1186/S12889-019-7406-9.

Kaye LK, Orben A, Ellis DA, Hunter SC and Houghton S (2020). The Conceptual and Methodological Mayhem of 'Screen Time'. Int J Environ 2020, Vol. 17, Page 3661, 17(10): 3661. doi: 10.3390/IJERPH17103661.

Kelly T, Yang W, Chen CS, Reynolds K and He $J$ (2008). Global burden of obesity in 2005 and projections to 2030. Int $\mathrm{J}$ obes (2005), 32(9): 1431-1437. doi: 10.1038/IJO.2008.102.

Krebs NF, Himes JH, Jacobson D, Nicklas TA, Guilday P and Styne D (2007). Assessment of Child and Adolescent Overweight and Obesity. Pediatrics, 120(Supplement_4): S193-S228. doi: 10.1542/PEDS.2007-2329D.

Kumar S and Kelly AS (2017). Review of Childhood Obesity: From Epidemiology, Etiology, and Comorbidities to Clinical Assessment and Treatment. Mayo Clinic proceedings, 92(2): 251-265. doi: 10.1016/J.MAYOCP.2016.09.017

Kurdanti W, Suryani I, Syamsiatun NH, Siwi LP, Adityanti MM, Mustikaningsih D and Sholihah KI (2015). Faktor-faktor yang mempengaruhi kejadian obesitas pada remaja (Factors that influence the incidence of obesity in adolescents). JGKI, 11(4): 179-190. Available at: https://jurnal.ugm.ac.id/jgki/article/view/22900 (Accessed: 9 November 2021).

Kurniawan F (2018). Program sehat cegah obesitas pada anak (Healthy program 
to prevent obesity in children). UGM.

Lamboglia CMGF, Silva VTBL Da, Vasconcelos Filho JE De, Pinheiro MHNP, Munguba MCDS, Silva Júnior FVI, Paula FAR De and Silva CAB Da (2013). Exergaming as a strategic tool in the fight against childhood obesity: a systematic review. J obes, 2013. doi: $10.1155 / 2013 / 438364$.

Martens L, De Smet S, Yusof MYPM and Rajasekharan S (2017). Association between overweight/obesity and periodontal disease in children and adolescents: a systematic review and metaanalysis. Eur Arch Paediatr Denty, 18(2): 69-82. doi: 10.1007/S40368017-0272-1.

Md M and Islam S (2020). The Impact of Fast Food on Our Life: A Study on Food Habits of Bangladeshi People. GJMR, 20(8).

Mekonnen T, Tariku A and Abebe SM (2018). Overweight/obesity among school aged children in Bahir Dar City: cross sectional study. Ital $J$ Pediatr, 44(1). doi: 10.1186/S13052018-0452-6.

Mihrshahi S, Drayton BA, Bauman AE and Hardy LL (2017). Associations between childhood overweight, obesity, abdominal obesity and obesogenic behaviors and practices in Australian homes. BMC public health, 18(1). doi: 10.1186/S12889-017-4595-Y.

Moher D, Liberati A, Tetzlaff and D Altman (2009). Preferred Reporting Items for Systematic Reviews and MetaAnalyses: The PRISMA Statement.

Murti B (2018). Prinsip Dan Metode Riset Epidemiologi (V). UNS.

Nittari G, Scuri S, Sagaro GG, Petrelli F and Grappasonni I (2020). Epidemiology of Obesity in Children and Adolescents. Teamwork in Healthcare. doi: 10.5772/INTECHOPEN.93604.

Paduano S, Borsari L, Salvia C, Arletti S, Tripodi A, Pinca $\mathrm{J}$ and Borella $\mathrm{P}$ (2020). Risk Factors for Overweight and Obesity in Children Attending the First Year of Primary Schools in Modena, Italy. J Community Health, 45(2): 301-309. doi: 10.1007/S10900-019-00741-7.

Paduano S, Greco A, Borsari L, Salvia C, Tancredi S, Pinca J, Midili S, Tripodi A, Borella P and Marchesi I (2021). Physical and Sedentary Activities and Childhood Overweight/Obesity: A Cross-Sectional Study among FirstYear Children of Primary Schools in Modena, Italy. IJRPH 2021, Vol. 18, Page 3221, 18(6): 3221. doi: 10.3390/IJERPH18063221. 